\title{
Consumers' trade-off between relationship, service package, and price : an empirical study in the car industry
}

Citation for published version (APA):

Odekerken-Schröder, G. J., Ouwersloot, J., Lemmink, J. G. A. M., \& Semeijn, J. (2002). Consumers' trade-off between relationship, service package, and price : an empirical study in the car industry. METEOR, Maastricht University School of Business and Economics. METEOR Research Memorandum No. 089 https://doi.org/10.26481/umamet.2002089

Document status and date:

Published: 01/01/2002

DOI:

10.26481/umamet.2002089

Document Version:

Publisher's PDF, also known as Version of record

\section{Please check the document version of this publication:}

- A submitted manuscript is the version of the article upon submission and before peer-review. There can be important differences between the submitted version and the official published version of record. People interested in the research are advised to contact the author for the final version of the publication, or visit the DOI to the publisher's website.

- The final author version and the galley proof are versions of the publication after peer review.

- The final published version features the final layout of the paper including the volume, issue and page numbers.

Link to publication

\footnotetext{
General rights rights.

- You may freely distribute the URL identifying the publication in the public portal. please follow below link for the End User Agreement:

www.umlib.nl/taverne-license

Take down policy

If you believe that this document breaches copyright please contact us at:

repository@maastrichtuniversity.nl

providing details and we will investigate your claim.
}

Copyright and moral rights for the publications made accessible in the public portal are retained by the authors and/or other copyright owners and it is a condition of accessing publications that users recognise and abide by the legal requirements associated with these

- Users may download and print one copy of any publication from the public portal for the purpose of private study or research.

- You may not further distribute the material or use it for any profit-making activity or commercial gain

If the publication is distributed under the terms of Article $25 \mathrm{fa}$ of the Dutch Copyright Act, indicated by the "Taverne" license above, 


\section{CONSUMERS' TRADE-OFF BETWEEN}

\section{RELATIONSHIP, SERVICE PACKAGE, AND PRICE:}

\section{An empirical study in the car industry}

Gaby Odekerken-Schröder ${ }^{1}$, Hans Ouwersloot ${ }^{2}$, Jos Lemmink ${ }^{3}$, Janjaap Semeijn ${ }^{4}$

Key words: consumer decision making, car industry, relationship marketing, conjoint analysis, cluster analysis, segmentation

Word count: 10,421

1 Corresponding author: Assistant Professor of Marketing at the Faculty of Economics and Business Administration, Maastricht University, P.O. Box 616, 6200 MD Maastricht (the Netherlands), e-mail: g.schroder@mw.unimaas.nl, tel. +31 43388 3618, fax +31433884918 Assistant Professor of Marketing at the Faculty of Economics and Business Administration, Maastricht University Professor of Marketing at the Faculty of Economics and Business Administration, Maastricht University

4 Associate Professor of Logistics at the Faculty of Economics and Business Administration, Maastricht University 


\title{
CONSUMERS' TRADE-OFF BETWEEN \\ RELATIONSHIP, SERVICE PACKAGE, AND PRICE:
}

An empirical study in the car industry

\begin{abstract}
The prime objective of our study is to assess whether consumer segments based on relational aspects, service aspects, or price aspects have different preferences concerning these three key decision making variables when buying a car. In addition, we assessed consumer segments resulting from simultaneously incorporating relationships, service package, and price. We investigated a large sample of Mitsubishi drivers in the Netherlands emphasizing consumers' trade-off between dealer relationship, service package and price. Conjoint analysis showed that dealer relationships (as opposed to price) represent a very important decision making variable when buying a car and consumer preferences concerning relationships provide a useful instrument for segmenting markets. Cluster analyses on the basis of three aspects simultaneously revealed that some consumers do value relationships, while others emphasize the service package in their purchase, both opposed to the third segment that is most probably not inclined to be loyal to a car dealer at all.

Our study clearly indicates that different consumer segments can be distinguished on the basis of preferences for relationships and service packages rather than on the basis of price. This knowledge enables car dealers to use their resources more effectively.
\end{abstract}


CONSUMERS' TRADE-OFF BETWEEN RELATIONSHIP, SERVICE PACKAGE, AND PRICE: AN EMPIRICAL STUDY IN THE CAR INDUSTRY

1. Introduction

Recent research has emphasized the importance of relationship marketing (Garbarino and Johnson, 1999; Morgan and Hunt, 1994) and many firms have increasingly been devoting considerable attention to developing and maintaining close relationships with their customers, in order to create value by differentiating their offering and/or lowering their costs (Weitz and Bradford, 1999). Even in the car industry, which could formerly be characterized by a product orientation, establishing long-term relationships is currently deemed to be essential at all levels of the distribution channel, although it is still a difficult process in this industry focused on mass production. As a result of this, knowledge about consumers and addressing their needs is considered to contribute to a car dealer's competitive advantage (Chojnacki 2000). Especially for Europe in the twenty-first century, the strategic question of how to compete is more vivid than ever. This is rooted in the increasingly deregulated environment in the European Union and a rapidly increasing sales volume via the Internet. Therefore, knowledge about key decision-making variables of consumers is crucial.

In making a purchase, consumers usually take several dimensions into consideration. Being aware of the dimensions that are crucial in the eyes of the consumer would enable car dealers to use their resources most effectively. In general two different types of benefits or values are involved in a purchase: acquisition value and exchange value (Fontenot and Wilson 1997; 
Frenzen and Davis 1990). Sharma and Patterson (1999) likewise make a distinction between technical aspects and functional aspects. In the same sense, Jüttner and Wehrli (1994) referred to the difference between the exchange object and the exchange process. All classifications have in common that the first aspect is related to the goods themselves, while the second refers to everything surrounding the purchase (Frenzen and Davis 1990). In addition to this, relational aspects have become an important third means of competitive differentiation (Storbacka et al., 1994). This can be attributed to two main developments. First, consumers' quality expectation levels have risen as consumers have gradually become more knowledgeable and sophisticated (Jüttner and Wehrli, 1994). Acceptable levels of technical and functional aspects might be considered as minimal conditions for consumers to engage in exchanges (Crosby et al., 1990). Second, car dealers are increasingly competing with each other on the basis of the same or highly comparable marketing tactics and strategies. Typically, they copy competitors' pricing strategies, and treat their consumers well in terms of services offered (Berry and Gresham, 1986; Davis, 1997). Hence, technical and functional aspects must be supplemented by an emphasis on relational aspects to differentiate their offerings.

It is generally recognized that sellers have a portfolio of different types of relationships with their consumers, partially depending upon the personal preferences of the respective buyers. Some of these relationships are based on transactional exchanges and others are based on relational exchanges.

MacNeil (1980) was the first to make a distinction between discrete exchanges and relational exchanges. An exchange is considered to be discrete when it is separated from all else between exchange partners before, during, and after the exchange (Frazier, Spekman, and O’Neal 1988; Lusch and Brown 1996; MacNeil 1980; Robicheaux and Coleman 1994; 
Rylander, Strutton, and Pelton 1997). In other words, a discrete exchange is evaluated independently without any reference to those transactions that have been realized before and to those transactions that are yet to come. It is a one-time utility-driven exchange of value between two parties with no prior or subsequent exchange (Fontenot and Wilson 1997; Hinde 1979; Morgan and Hunt 1994; Webster 1992; Weitz and Jap 1995). In contrast, the main characteristic of a relational exchange is its position in a history of previous exchanges and an anticipated future of expected exchanges. Relational exchange is assessed not in isolation, but as a continuation of past exchanges likely to continue in the future (Anderson 1995; Czepiel 1990; Dwyer, Schurr, and Oh 1987; Iacobucci and Ostrom 1996). While transactional exchanges may dominate the portfolio of most sellers, relational exchanges provide the greatest opportunity for developing strategic advantage (Weitz and Bradford, 1999) and profits on the somewhat longer term (Reichheld and Schefter, 2000). In line with this, Barnes (1997) argued that not all buyers want a relationship with a seller. There is even anecdotal evidence, especially in the automobile industry, that establishing long-term relationships with existing consumers can lead to reduced gross margins in some cases (Day, 1990; Helper 1991; Lyons, Krachenberg, and Henke 1990 in Kalwani and Narayandas 1999). Despite its recognized importance, no study has yet empirically investigated the potential impact of buyers' interest in an enduring relationship on their preferences and their perceptions of the seller (Sheth and Parvatiyar 1995). Fournier, Dobscha, and Mick (1998, p. 42) recently pointed to this issue by stressing that

"Caught up in our enthusiasm for our information-gathering capabilities and for the potential opportunities that long-term engagements with customers hold, is it possible that we have forgotten that relationships take two?"

Therefore, the role of relationships, compared to other decision variables, warrants further investigation. It is deemed interesting to investigate whether consumer segments based upon 
relationships (representing relational aspects), service aspects (representing functional aspects) or price aspects (representing technical aspects) have different preferences concerning these three key decision making variables we identified.

The remainder of this paper is structured as follows. First, we provide a theoretical background and discuss our conceptual model and related research hypotheses. Subsequently, we describe the applied research methodology and discuss the results. In the final section, we elaborate on the study's managerial implications for the car industry and provide directions for future research.

\section{Relationship marketing and buying decisions}

In the car industry, the key to successful relationship marketing rests at the dealer level. As far as the consumer is concerned, the dealer is the face of the company. How the dealer performs -either good or bad- is how the company will be viewed (Illingworth, 1991). Car dealers are increasingly confronted with more demanding and knowledgeable consumers, shortened product life cycles, crowded environments, undifferentiated product and pricing offerings, intensified competition, and market fragmentation (Woodruff, 1997). Driven by this evolution, a strategy that is increasingly being used by car dealers to position themselves more effectively in the marketplace is the continuous improvement of quality delivery (Sharma and Patterson 1999; Yoo et al., 1998). However, the way in which consumers make their purchase decision and how their loyalty can be maintained are still unresolved issues. It appears that, especially in the car industry, uncertainty and incorrect beliefs exist about what matters most to consumers. First, while a large body of knowledge is developing on quality management in manufacturing and services settings, systematic empirical research on quality 
issues in goods purchases is still in its early stages (Javalgi and Moberg, 1997). Nevertheless, quality enhancement is becoming increasingly important as most markets have reached maturity, are over-stored, and face difficulties differentiating themselves based on the product only (Berry and Gresham, 1986). A second point is that aspects not related to the pure technical or functional issues are gaining in importance, yet have received only limited attention. Especially in markets where sellers provide equally high levels of product or service aspects, focusing on complementary dimensions becomes an important means of gaining competitive advantage (Berry, 1995; Gwinner et al., 1998). While technical and functional aspects have received a large share of attention in marketing literature (Eriksson et al., 1999; Sweeney et al., 1999), it is increasingly recognized that they are only part of total quality (Fontenot and Wilson, 1997). Analogous to Kasper et al.'s (1999) suggestion to distinguish between technical, functional, and relational aspects, our study incorporates relational aspects as an additional element of importance in the purchase decision. It refers to the opportunity for consumers to affiliate with the car-dealer or a sales representative before, during or after the purchase encounter.

While technical, functional and relational aspects play a role in buying a car, we assume that their differential importance might be contingent upon the consumer's preferences with respect to long-term relationships. Despite its recognized importance, to the authors' knowledge no study has yet investigated the potential impact of buyers' proneness to engage in relationships (Sheth and Parvatiyar 1995) on the relative importance of these purchase dimensions.

\section{Conceptual model}


The description of dimensions that consumers consider in making a purchase is consistent with the generally accepted anatomy of a product model (Kotler 1997). This model depicts a product in three layers visualised in Figure 1. The first core layer consists of the core product. It is the fundamental features of what the consumer is buying and can be assumed to provide the technical benefits the buyer is looking for. In our study, the concept of price reflects the value consumers attach to the core technical aspect of an exchange. The second layer consists of the tangible or actual product. Everything that relates directly to the product but goes further than the fundamental characteristics belongs to the actual product. In our case of the car industry, warrantees and trade-in guarantees are part of the actual product: these features relate to the car, but are not part of the core product. The actual product strongly relates to the functional features of the purchase. The final layer consists of the augmented product. This includes all features that are of concern to buyer and/or seller, but are not directly related to the product. Examples are after-sales support and credit facilities. Many of these augmenting features are closely related to establishing a relationship between buyer and seller, and relational aspects fall into this domain.

\section{INSERT FIGURE 1 ABOUT HERE}

4. Measurement scales and Research hypotheses

\subsection{Measurement scales}

Although price is a rather limited view of technical quality, it is usually considered as a tradeoff between the financial offer a consumer is willing to pay in return for the perceived product value (Simon 1989). Hence, the sensitivity of the consumer to price changes reflects 
the importance consumers attach to the value of the core product. We made a distinction between two price levels. The first price level is the manufacturer's suggested retail price (MSRP) of a particular car. The second price level is equal to the MSRP of a particular car minus $4 \%$.

Next, we consider service package to be representing the functional aspects of the actual product offered by the car-dealer or sales associate (Crosby et al., 1990). Berry and Gresham (1986) suggested that many successful suppliers differentiate themselves from competitors not only through the offered technical aspects, but through the way in which they offer service. Therefore, functional aspects like service, have long been recognized as an important strategic weapon and is often regarded as a prerequisite to survive (Sharma and Patterson, 1999). Suppliers that offer poor service may undermine consumer attitudes, even when they provide good prices (Yoo et al., 1998). Especially in the interpersonal and dyadic nature of buying a car, service is deemed to be an important element (Mittal and Lassar, 1996). Three different levels of the service package were defined. The first level is called basic package, which consists of a 1,3 or 5-year guarantee on the car, excluding the cost of maintenance. The second level is called complete package meaning a 1,3 or 5-year guarantee on the car, including the cost of maintenance. The final level distinguished is labeled plus package implying a comprehensive service package consisting of a 1,3 or 5-year warrantee on the car, including an exchange guarantee, guarantee for fuel consumption, a pre-defined trade-in price after 1,3 or 5 years, but excluding cost of maintenance.

The third element incorporated in the purchase decision refers to relational aspects, which are regarded as the opportunity for consumers to affiliate with the car dealer or sales representative during or after the purchase encounter. Hence, they coincide with aspects typical of the augmented product. Consumers may thus perceive relational aspects as a result of consumer-provider interactions (Gwinner et al., 1998; Westbrook and Black, 1985). 
Relational aspects can be a source of comfort and may contribute to a feeling of belonging (Mittal and Lassar, 1996). Various authors have acknowledged the importance of relationships in influencing consumers' attitudes and loyalty. Loyalty has been recognized as essential to customer retention and therefore business survival (Jüttner and Wehrli, 1994, Reichheld and Schefter, 2000). Six types of relationships between the consumer and the car dealer can be distinguished (Kotler 1997). The first level, no contact, refers to a situation in which the consumer is not having a relationship with the car dealer at all. The most elementary relationship is called incidental relationship meaning that the car-dealer does not make any efforts towards the consumer after the purchase. The third relationship type can be labeled awaiting relationship and refers to a situation in which the car dealer tells the consumer that he should not hesitate to contact the dealer again, but the car dealer does not take proactive efforts himself. The fourth relationship level is the informative relationship. In this type of relationship a salesperson for example, phones the consumer a short time after the purchase to check whether the car is meeting the consumer's expectations. The salesperson might also ask for any suggestions or specific disappointments. This information helps the car dealer to improve its performance but the relationship stops after this one-time action. The fifth level is called enduring interest and represents a situation in which the car dealer frequently shows interest in the consumer and gives advice. The most far-reaching relationship level is the co-operative relationship in which the car dealer works together with the consumer to discover ways to effect consumer savings and treats the consumer in a rather personal way (Kotler 1997).

A summary of the measurement scales is provided in the Appendix.

\subsection{Research hypotheses}


An interesting question is which of the three distinguished aspects plays the most important role in buying a car. Knowledge about this would enable car dealers to allocate their marketing resources in an effective and efficient way and would result in an improved augmented product for the customer. Therefore, we formulated several hypotheses contributing to our understanding of the trade-off between the three important elements in the buying decision: relationship, service package and price. In addition, we want to demonstrate that different consumer segments can be distinguished revealing different preferences with respect to those aspects which influence the purchase decision and, in particular, with respect to the relational aspects.

Further, we want to investigate what information is needed to distinguish consumer segments. The three aspects are considered simultaneously in the buying process, but the importance of aspects can also be surveyed independently. Using partial information on the aspects is convenient and economical, but our question is whether a more thorough analysis provides additional insights. Hence, we compare the results of a stated preference approach for each of the three aspects in isolation, to the results of a (simulated) revealed preference approach that relies on conjoint analysis. ${ }^{1}$ We have developed four hypotheses and an additional research question that will be discussed subsequently.

The first hypothesis is based upon the premise that product offerings of different car dealers are highly comparable in the current environment. As a result, increased emphasis is placed upon the relationship between consumer and car dealer (Chojnacki 2000).

\footnotetext{
${ }^{1}$ Although conjoint analysis $(\mathrm{CA})$ is not a true revealed preference technique, it is closer to revealing true preferences than the common stated preference techniques. In market studies CA is highly appreciated by both practitioners and academics (Wittink et al. 1994)
} 
$\mathrm{H}_{1}$ : Relationships are more important than the offered service package or price as an aspect in the purchase decision of consumers buying a car.

As mentioned at the beginning of this paper, car dealers have a portfolio of different relationships with consumers (Weitz and Bradford, 1999). The different consumer segments that can be distinguished most probably have different preferences with respect to the aspects in the purchase decision of consumers buying a car. Therefore, we formulate the following hypotheses.

$\mathrm{H}_{2}$ : Consumer segments distinguished on the basis of stated preferences for the relationship aspect, can clearly be differentiated on their revealed preferences for the relationship aspect and can not be differentiated on their revealed preferences for the service package nor for price

$\mathrm{H}_{3}$ : Consumer segments distinguished on the basis of stated preferences for the service package, can clearly be differentiated on their revealed preferences for the service package and can not be differentiated on their revealed preferences for relationship nor for price

$\mathrm{H}_{4}$ : Consumer segments distinguished on the basis of stated preferences for the price aspect, can clearly be differentiated on their revealed preferences for the price aspect and can not be differentiated on their revealed preferences for relationship nor for service package 
A next step would be to ask whether it is appropriate to segment consumers on the basis of a partial analysis, including one dimension only. In order to test this, we use the results of the conjoint analysis, including all three aspects of a buying process simultaneously, as input for a cluster analysis. As this analysis is of an exploratory nature we formulate the following research question.

\section{Research Question:}

What consumer segments can be distinguished based upon relationships, service package and price simultaneously?

\section{Research design}

\subsection{Sample}

As part of a large-scale study at Mitsubishi, the data for our empirical research were collected in The Netherlands. Mail questionnaires were sent to 2012 Mitsubishi car owners. In order to investigate any brand specific differences on an elaborate set of variables an additional number of 600 questionnaires were sent to a sample of Opel, Volkswagen and Toyota car owners. The addresses were obtained from the Dutch State Institute for Road Transport. The response rate among Mitsubishi car owners was remarkably high, being 53\%, for the other car owners the average response rate was still 34\%. The high response rate for the Mitsubishi owners can be attributed to the offered incentive for participation, a discount on Mitsubishi accessories.

No statistical significant differences $(\alpha=0.05)$ were found regarding the means of most important variables in this research between Mitsubishi owners and owners of the other 
brands. Moreover, with regard to the Conjoint Analysis (CA) experiment no statistical significant differences $(\alpha=0.05)$ between part worths of the attribute levels could be traced across various brands. The demographic characteristics of the Mitsubishi and other car owners are very similar. In our study we concentrate on the Mitsubishi drivers only. The sample can be considered to be representative of the whole population of Dutch Mitsubishi drivers.

1070 Mitsubishi drivers returned the questionnaire, $86 \%$ of them being male. The age variable revealed that $32 \%$ of the respondents was 60 years and older, and the median was found in the 50-54 age category. The Mitsubishi drivers mainly use their car for private purposes. $68 \%$ reported only private usage and another $30 \%$ reported both private and business usage. Only $2.5 \%$ reported mainly business usage. This is also reflected in the reported mileage. Again $68 \%$ report an annual number of driven kilometres less than 20.000 , while another $21 \%$ reported between 20 and 30 thousand kilometres. The majority of Mitsubishi drivers replace their cars rather late: only 2,7\% replace their car within 2 years, $28,2 \%$ between 2 and 3 years, $51 \%$ report replacement after 3 to 5 years, $17 \%$ after 5 years or more. $93 \%$ have ever driven another brand, which is not remarkable given the high age of the respondents. Over $60 \%$ are currently driving their first or second Mitsubishi ever. Finally, 768 respondents completed the part of the questionnaire with the conjoint analysis $(72 \%)$. In the remainder of this paper, this reduced sample will be used, as it does not differ significantly from the complete sample of Mitsubishi drivers in terms of the variables: gender, age, purpose of car usage, mileage, replacement and first or second Mitsubishi ever.

\subsection{A priori segmentations}


In order to test Hypotheses 1 - 4, we used Conjoint Analysis to assess the trade-offs between the three distinguished aspects: relationship, service package and price. The a priori segments are subsequently distinguished on the basis of one of the three aspects and their respective levels. Based on the stated consumer preferences towards the relationship between consumer and dealer three segments could a priori be defined, weak relationship, improving relationship, and strong relationship. This segmentation is based on a two-way classification of the type of relationship between dealers and consumers, long-term and short-term oriented. A short-term orientation corresponds to the first three levels of the relationships types as defined (no contact, incidental and awaiting). A long-term orientation implies one of the three remaining relationship types (informative, enduring interest and co-operative). When a consumer perceives the relation to be short-term oriented and does not expresses a wish to turn this into a long-term relationship, it is classified in the weak relationship category. When the perceived and desired relationship are both long-term oriented, the appropriate category is the strong relationship. The improving relationship category consists of those consumers who perceive the relationship as short-term oriented, whereas they prefer a long-term relationship. The fourth logical group, from long-term to short-term orientation, consisted of 8 respondents only and was therefore not treated as a separate segment.

Similarly, price sensitivity was investigated. Respondents were asked whether they would do business with their dealer in two different situations. First, they were offered a car for a fixed price, equal to the MSRP. Second, the price was MSRP minus 4\%. Again a three-way a priori classification emerged, those who never would do business, those who would start doing business in both situations and the third group that turned out to be price-sensitive. The fourth group that displayed a perverse price sensitivity (do business in case of the MSRP, and not in case of the $4 \%$ reduction) was again not defined as a separate segment ( 19 respondents only). 
Also the attitude towards service packages was investigated. However, the data revealed that the relevant question was not well understood by the respondents ${ }^{2}$. As can be seen in the appendix, this question most probably required too much effort by the respondent and therefore reveals a high level of non-response. Hence, no a priori classification with respect to preferences of service packages was made and so, hypothesis 3 could not be tested.

\subsection{Revealed preferences and segmentation}

For the relational aspect we incorporated three levels in the conjoint analysis being the incidental, informative and co-operative relationship, ranging from the transactional end of the relationship spectrum to the relational end. Furthermore, we distinguished between three service packages: standard, plus and complete. Finally we discriminated between the MSRP and a $4 \%$ price discount. Subsequently, in the questionnaire we used a full $3 \times 3 \times 2$ fractional factorial design.

The data of the Conjoint Analysis (CA) experiment are used to estimate the relative importance of the relationship, the service package and the price. CA is a technique to estimate for each attribute (in this case the attributes are relationship, service package, and price) the relative utilities of the corresponding levels (e.g. in this case the levels of service package are standard, plus, and complete) (Wittink et al. 1994). These relative utilities are called part worths. Part worths can be calculated in such a way that within an attribute they add up to zero. Part worths are comparable across attributes. Suppose for example that the part worth of level 1 of attribute A is higher than the part worth of level 2 of attribute B. Then

\footnotetext{
${ }^{2}$ On average $50 \%$ of the observations was missing for this question that consists of several items. Moreover, the non-missing observations showed patterns that suggest that the respondents could not cope with the concepts underlying the question. The question involved asked what price people were willing to pay for various service
} 
it can be concluded that level 1 of attribute 1 contributes more to the utility of the respondent than level 2 of attribute B. Finally, similar comparisons are valid across individuals or groups. In order to test Hypothesis 3, we used the results of the CA as input for a cluster analysis (Punj and Stewart 1983), developing consumer segments on the basis of revealed preferences.

6. Results

\subsection{Conjoint Analysis}

Part worths are estimated for each individual separately. To compare groups or segments the average part worths are calculated. Table 1 shows part worths for all respondents within the sample. Kendall's tau for the whole sample was 0.67 , significant at the $1 \%$ level, indicating an appropriate goodness of fit (Leigh et al. 1984). These part worth estimates allow some interesting direct interpretations. Within the attributes, the results are not surprising. A standard service package is valued less than a plus package, which again is preferred less compared to a complete package. Similarly, on average people do not like incidental relationships, but rather prefer informative and - even better - a cooperative relationship with the dealer. And obviously a $4 \%$ price reduction is well liked. More interesting observations emerge from comparisons across attributes. The increase in utility of offering a complete service package instead of a standard package (.605 utility points) compares to the utility of a price reduction of $4 \%$ of the MSRP (.520 utility points). However, the relationship attribute is much more valuable to the average consumer, evidenced by a potential increase of 2.38 utility points when changing an incidental relationship into a cooperative one. This confirms 
our first hypothesis: relational aspects are more important than the offered service package or price as an aspect in the purchase decision of consumer buying a car.

\section{TABLE 1 ABOUT HERE}

Table 2 presents results of the analysis for the a priori defined segments based on the stated preferences for the relationship aspect. The results demonstrate that there are differences across the three relationship groups. The strong relationship segment is much more pronounced, given the wider range of part worths compared to the other consumer segments. This is mainly caused by an increased importance attached to the type of relationship attribute. Another striking result is that in absolute terms the price attributes essentially gets the same part worth values across segments. Given that relationship becomes increasingly important for the improving relationship and strong relationship segments, it also means that the price attribute is the most important to the weak relationship segment. This can also be observed in Figure 2, that depicts the three segments in a weight triangle

Each point of this triangle represents a combination of weights, attached to relationships, service and price. The three weights add to one. In each of the three corners, a weight of 1 is given to the aspect of that corner, while consequently the other aspects get a weight of 0 . So, when a group of consumers makes a decision, based on relational aspects only (giving no importance to the price or service aspects) this group of consumers will be located in the top corner of the triangle. That place represents a situation where relational aspects get a weight of 1 and the other aspects a weight of 0 .

The sides of the triangle represent all combinations of weights for which the weight of the label of the opposite corner is 0 . So, the base of the triangle in Figure 2 consists of all combinations of weights for which the relational aspect receives a zero weight. Going from a 
corner to the opposite side of the triangle means that the weight attached to the related aspect decreases. Hence, going from the top corner labelled relationship, to the opposite edge of the triangle implies that the weight attached to the relationship aspect decreases.

All locations in the interior area of the triangle are those combinations of weights for which none of the aspects receives a zero weight. In particular the centre point of the triangle is the point where all three aspects receive an equal weight: $1 / 3$ or 0.333 for relation, price and service aspects.

\section{INSERT TABLE 2 AND FIGURE 2 ABOUT HERE}

Locating a segment of consumers, within this triangle gives information about the weights, this segment attaches to each of the three aspects. This representation provides an opportunity to visualize information on the importance of the aspects to consumers. The three a priori defined segments are clearly distinct in the relation dimension, and are undifferentiated in the service dimension. The exclusive position of the low-level segment in the price dimension is clear. This provides support for hypothesis 2. This indicates that consumer segments distinguished on the basis of stated preferences for the relationship aspect can clearly be differentiated on their revealed preferences for the relationship aspect and can not be differentiated on their revealed preferences for the service package nor for price.

To investigate whether the differences across consumer segments are statistically different, we apply MANOVA (see Table 2). When we investigate the differences for all variables simultaneously we conclude that the differences are significant (MANOVA, $\mathrm{p}<0.00$ ). Further tests reveal that for the service package group of variables (MANOVA, $p=0.01$ ) and the relationship variables (MANOVA, $\mathrm{p}<0.00$ ), the differences across the consumer 
segments were significant. On the other hand, no significant differences for the Price variable (ANOVA, $\mathrm{p}=0.36$ ) are found.

Table 3 shows the average part worths for the three identified price segments. Testing all variables simultaneously shows that the differences between the consumer segments are not significant (MANOVA, $\mathrm{p}=0.57$ ). Also when we look at the differences for the three groups of variables separately, we again cannot detect any significant differences (MANOVA, $\mathrm{p}=$ 0.27 for the service package variables, $p=0.95$ for the relationship variables and $p=0.16$ for the price variables). As a result, we cannot support hypothesis 4 in which we hypothesized that consumer segments distinguished on the basis of stated preferences for the price aspect, can clearly be differentiated on their revealed preferences. Figure 3 depicts the price segments in the weights triangle.

\section{TABLE 3 AND FIGURE 3 ABOUT HERE}

\subsection{Cluster Analysis}

In order to explore the formulated research question we look for customer segments based on the estimated part worths (by simultaneously assessing relationship, service package and price), instead of working with predefined consumer segments. These part worths reveal the preferences of the respondents and may therefore provide different information than the stated preferences, upon which the predefined segments are based. Therefore, the CA results will be used as input for a cluster analysis rather than the raw data scores, as our objective is to find customer segments based on revealed behaviour. Using raw scores on the conjoint analysis as input for a cluster analysis would not provide any insights in the relative utilities 
of the distinguished levels of relationship, service package, and price. Segmenting on CA is a useful approach since the CA analysis gives information about the importance clients attach to their relationship with the dealer, hence, are closely related to the fundamental marketing principle of looking to consumer needs and wants.

First, a cluster analysis is applied based on the part worths. Ward's method was applied with squared Euclidean distance as the metric. We fine-tuned the solution of this agglomerative procedure by applying a K-means algorithm. We verified that there were no problems with outliers.

The agglomeration schedule suggested either a three-, or a four-cluster solution. Applying Kmeans revealed that the four-cluster solution was not stable. The observations of one of the clusters resulting from the agglomertive procedure were scattered over all four clusters of the K-means solution. This problem did not occur with the three-cluster solution. Moreover, the three-cluster solution had a clear and meaningful interpretation of all clusters, whereas for the four cluster solutions, two of the clusters were difficult to distinguish when interpreting the solution (see below).

To further assess the (internal) validity of the solution we performed two different stability tests. The first stability test incorporated running the three-cluster solution of the K-means procedure with two different sets of starting points. One set was chosen at random, the other set consisted of the centroids of the three clusters from Ward's method. Both clustering algorithms ended with exactly the same cluster solution. The second stability test was conducted by repeating the clustering for two sub samples, each consisting of a random split of approximately half of the original observations. For both samples the same solution was found, in terms of characteristics of the final clusters. 
Mean values of the part worths for the three clusters are given in Table 4. Pseudo tests (MANOVA and ANOVA) suggest that the three clusters are genuinely different for the given variables. MANOVA and ANOVA are not true tests because the groups were formed with the help fo the variables that are under consideration. Consequently the data do not meet the assumptions of the procedures, in particular the normality assumption is violated. Nevertheless we applied this technique for sake of comparison with the other tables, and because this test is closely related to the test suggested by Punj and Stewart (1983). In the discussion below it will also become clear that the identified clusters are also meaningful and useful, which is an important aspect in assessing the external validity of the analysis (Punj and Stewart, 1983).

A graphical representation of the relative weights attributed by the three segments is provided in Figure 4. The first cluster is characterized by its strong emphasis on a cooperative relationship. For the other attributes this cluster shows average values and very small weights. The second and third clusters both attach heavy weight to the service aspect. However, they have opposite interests when it concerns the service package. Cluster two wants a complete service package, whereas cluster three on the contrary has a strong preference for a standard package. Moreover, cluster two displays the strongest response to the price differential, cluster three again on the contrary weak price sensitivity, although the weights on this aspect do not differ substantially.

FIGURE 4 ABOUT HERE

Comparing Figure 4 to Figures 2 and 3, and also Table 4 to Tables 2 and 3 strongly suggests that the initial consumer segments, on the basis of one aspect only, differ substantially from the ultimate consumer segments, on the basis of three aspects simultaneously. Segmentation 
based on the preferences that are revealed while simultaneously assessing the importance of the aspects involved in the exchange, is different from segmentation based on the assessment of one aspect at a time.

7. Discussion, managerial implications and suggestions for further research

\subsection{Discussion}

The prime interest of this paper was to investigate whether consumer segments based upon relational aspects, service aspects or price aspects have different preferences concerning these three key decision making variables. In addition, we investigated what consumer segments could be distinguished based upon examining the three key decision making variables simultaneously. The conceptual idea underlying our research is in line with the anatomy of a product model, which consists of price, service package and relationships in our application.

In line with Barnes (1997) who argued that not all consumers want a relationship with a seller, our data show that relational preferences are a strong factor in distinguishing between different consumer segments. Compared to service package and price, consumers attach the most importance to relationships in making a purchase. This is in line with Chojnacki (2000) who stated that relationships between car dealers and consumers are increasingly important. Similar to Weitz and Bradford (1999), our study further indicated that on the basis of relationship several consumer segments can be distinguished, ranging from consumers desiring a weak relationship to consumers desiring a strong relationship. For car dealers in the twenty-first century it is important to realize that not every consumer desires a strong 
relationship. Recognizing these differences among consumers will enable car dealers to use their resources more efficiently in the future (Hennig-Thurau, Gwinner and Gremler 2000). Moreover, our study provides empirical evidence for the limited value of price as a segmentation criterion in the current car industry, supporting Crosby et al.'s (1990) assumption that price might be considered as a minimal condition for consumers to engage in exchanges. It turned out that consumer segments based upon price only, do not reveal differences in the importance attached to relationship, service package or price. Intensified competition, undifferentiated product and pricing offerings and knowledgeable customers may affect the decreasing value of price preferences as a segmentation criterion (Woodruff 1997).

In line with Kasper et al.'s (1999) conceptual distinction between technical, functional, and relational aspects, we assessed the consumer segments resulting from simultaneously incorporating relationship, service package and price in addition to investigating one segmentation variable at a time. This analysis resulted in three different consumer segments. The first segment can be considered as a segment valuing enduring relationship, while the second consumer segment basically focuses on the service package. In fact, the third consumer segment is an a-typical group of consumers. A price differential may be due to this group's somewhat odd preferences but then again the third consumer segment is least price sensitive. A possible explanation might be that this group presumes an implicit price to be paid for the service package (although this is not assumed in the questionnaire). Additionally it might be the case that this consumer segment considers a more extensive service package as an implicit contract to the dealer leaving little room to look for other ways to take care of maintenance and repair of their car. This consumer segment then appears to resist implicit as well as explicit involvement. Consequently the first cluster can be called "relationship- 
prone", the second "service-lookers" and the third "butterflies" (Reichheld and Schefter, 2000), or alternatively coined "free-riders".

Apparently the outer layer in the anatomy of a product model, relationship in our study, is a salient aspect in purchasing a car. In response to Sheth and Parvatiyar (1995) who assumed that the effects of seller efforts and resources can be tempered or strengthened by the consumer's level of relationship proneness, our study shows that by using only relational aspects as a segmentation criterion a car dealer might distinguish between different consumer segments, valuing relationships differently. However, segmenting a target market on the basis of three aspects simultaneously revealed that some consumers do value relationships, while others emphasize the service package in their purchase, both opposed to the third group that is most probably not inclined to be loyal to a car dealer at all.

\subsection{Managerial implications}

The car business is changing. Those players that are actively and dynamically evolving and anticipating the new requirements have the best chances. The implications to car dealers and the other players in the car industry are far reaching.

The traditional short term, indifferentiated- to- consumers focus of car dealers, on prices and margins, income from accessories, dealer add-on services and warranty work, is gradually shifting to more long term high involvement relationships with individual consumers. Factors such as knowing the consumer, empathy, responsiveness, and trust are important in such a relationship driven focus. In the present highly competitive environment dealers are, in fact, being squeezed on every aspect of their traditional earnings ability: margins per car, bonusses on volume shipped, service and repair income. Manufacturers are actively looking 
for ways to streamline distribution, and on-line services such as One-Swoop and Autobytel are gaining popularity, and appear to redefine car buying expectations.

With relationships featuring so high among determining factors in consumer behaviour the car dealers still appear well positioned to fulfil the role of establishing long-term relationships. Where the transaction and advisory role of the dealer may become less because of the Internet, the trusted and helpful (being there for the consumer) role is squarely with the dealers. This development also implies a movement towards consolidation among dealers, favouring dealers with the knowledge and resources for an individualized customer-oriented approach, and leaving traditional dealers with few options. The question is not: how can loyalist/relationship tendencies be catered to most conveniently, but, how can loyalty be created through a consistently satisfying experience. Loyalty is about earning the trust of the right kinds of consumers (Reichheld and Schefter, 2000). The most important consumer group is the segment interested in developing the relationship. Based on our study this group can be further characterized by low emphasis on price and significant interest in certain service packages: such is the implied trust in the car brand and car dealer that lessencompassing service packages seem to be sufficient by relationship-oriented buyers.

To a car manufacturer, the creation of loyalty and trust among its consumers is most important. In the past, and in varying degrees still today, these relationship-intensive marketing aspects were handled by proxy, relying on qualified dealers, in position to establish personal contacts. The results (of relying on these dealers and in some cases special import sales organizations) are mixed, and have come at considerable cost, part of overall distribution costs. Manufacturers are keen to lower these distribution costs as alternative channels become available.

New channels have become available to create the required consistently superior experience, with a new role for dealers. It is conceivable that future dealer organizations would not 
derive income from the sale of cars per se, but only through after sale services. Earning trust and loyalty then becomes an essential skill to remain in business.

Convenience (One-Stop Shopping) is the driving force in commercial settings involving loyalty and relationships. Consumers will become much more knowledgeable about cars, car buying and the different options associated with the process. Dealers will redefine their role as well-positioned essential service providers. Both manufacturers and a growing number of third party knowledge providers will be eager to assist in the process through highly customized websites. Whether it is the consumer looking for new model descriptions and/or experiences (such as $3 \mathrm{~d}$ virtual tours), or the dealer requesting information, parts or brochures anticipating consumer needs, manufacturers, remaining enlightened dealers and other channel intermediaries must take these developments into account and anticipate consumers' questions and needs in the most convenient way possible.

\subsection{Limitations and suggestions for future research}

Our research should be seen as a preliminary attempt at addressing an issue that has important implications for marketing theory and practice. Any preliminary attempt will involve a number of limitations. However, acknowledgement of these limitations also suggests new directions for future studies. A first potential shortcoming in the study is common method bias. As we used one single questionnaire to measure all constructs included, the relationships between these constructs may be somewhat inflated. No database information could be used as input for measuring actual behaviour. This study could be improved with access to more substantial data on customer purchase histories that are not subject to potential recall loss. It would then be possible to look at longer strings of purchases and to perhaps incorporate contextual information. With respect to the measurement items, 
we have to conclude that our item used to measure the stated preference for service packages was inappropriate. Apparently this question was confusing and complicated and required too much effort of the respondent. In a follow-up study we have to develop a more appropriate question, enabling us to test our hypothesis involving the service package related to a car purchase. Moreover, it must be recognized that our sample of Mitsubishi drivers in the Netherlands cannot necessarily be generalized. This limits the findings as relevant only to these types of consumers and car dealers. Future studies need to assess the generalizability of our findings to other contexts. Furthermore, future research should concentrate on issues that could help management identifying, attracting and retaining the "relationship-oriented" market segment. For managers it is important to recognize those players in the distribution channel that are instrumental for offering superior experience to consumers. Future research should shed light on issues as how to actively reward these players while eliminating others. Finally, dealers should focus on profitable service activities, based on knowledge of the consumer and added value through personal relationships with loyal consumers. Therefore, in future research a broader set of variables that are important to consumers in buying situations will be needed.

In conclusion, it is hoped that these research results will serve as a stimulus for additional empirical research involving relationships in the durable goods purchasing decisions. Further research into the role of relationships in car buying and its expected importance in the Internet era is required. We recommend a follow up study taking into account the suggested broader set of buying-decision variables as well as extension to multiple distribution channels, including Internet. 


\section{References}

Anderson, J.C., (1995) "Relationships in business markets: exchange episodes, value creation, and their empirical assessment", Journal of the Academy of Marketing Science, Vol 23 No 4, pp.346-350

Barnes, J.G. (1997) "Closeness, strength, and satisfaction: examining the nature of relationships between providers and financial services and their retail customers," Psychology and Marketing”, Vol 14 No 8, pp.765-90

Berry, L.L. and L.G. Gresham (1986), "Relationship retailing: transforming customers into clients", Business Horizons, Vol 29 (November-December), pp. 43-47

Berry, L.L. (1995), "Relationship marketing of services - growing interest, emerging perspectives", Journal of the Academy of Marketing Science, Vol 23 No 4, pp. 236-45

Chojnacki, K. (2000), "Relationship Marketing at VOLKSWAGEN", in Relationship Marketing: Gaining Competitive Advantage Through Customer Satisfaction and Customer Retention, Hennig-Thurau, T. and U. Hansen, Springer, Berlin, pp. 49-59

Crosby, L.A., R.A. Kenneth and D. Cowles (1990) "Relationship quality in services selling: an interpersonal influence perspective", Journal of Marketing, Vol 54 No 3, pp. 68-81

Czepiel, J.A. (1990), "Service encounters and service relationships: implications for research", Journal of business research, Vol 20 No 1, pp. 13-21

Davis, J.F. (1997), "Maintaining customer relationships through effective database marketing: a perspective for small retailers", Journal of Marketing Theory and Practice, Vol 5 No 2, pp. 31-42

Day, G.S. (1990), Market driven strategy - process for creating value, The Free Press, New York

Dwyer, F.R., Schurr, P.H. and S. Oh (1987) "Developing Buyer-Seller Relationships", Journal of Marketing, Vol 51 No 2, pp. 11-28

Eriksson, K., A. Majkgard, and D.D. Sharma (1999) "Service quality by relationships in the international market," Journal of Services Marketing, Vol 13 No 4,5, pp. 361-375

Fontenot, R.J. and E.J. Wilson (1997) "Relational exchange: a review of selected models for a prediction matrix of relationship activities", Journal of Business Research, Vol 39 No1, pp. 5-12

Fournier, S., S. Dobscha, and D.G. Mick (1998), "Preventing the premature death of relationship marketing”, Harvard Business Review, Vol 76 (January-February), pp.42-50

Frazier, G.L., R.E. Spekman and C.R. O’Neal (1988) "Just-in-time exchange relationships in industrial markets”, Journal of Marketing, Vol 52 (October), pp. 52-67 
Frenzen, J.K. and H.L. Davis (1990), "Purchasing behavior in embedded markets", Journal of Consumer Research, Vol 17 No 1, pp. 1-12

Garbarino, E. and M.S. Johnson (1999), "The different roles of satisfaction, trust, and commitment in customer relationships", Journal of Marketing, Vol 63 (April), pp. 70-87

Gwinner, K.P., D.D. Gremler, and M.J. Bitner (1998), "Relational benefits in services industries: the customer's perspective", Journal of the Academy of Marketing Science, Vol 26 No 2, pp. 101-14

Hart, C., N. Doherty and F. Ellis-Chadwick (2000) "Retailer adoption of the Internet: implications for retail marketing”, European Journal of Marketing, Vol 34 No 8, pp. 954974

Helper, S. (1991) "How much has really changed between U.S. automakers and their suppliers?”, Sloan Management Review, Vol 32 (Summer), pp. 15-28

Hennig-Thurau, T., K.P. Gwinner and D.D. Gremler (2000) in Relationship Marketing: Gaining Competitive Advantage Through Customer Satisfaction and Customer Retention, Hennig-Thurau, T. and U. Hansen, Springer, Berlin, 369-393.

Hinde, R.A. (1979), Towards Understanding Relationships. London, Academic Press.

Iacobucci D. and A.L. Ostrom (1996), "Commercial and Interpersonal Relationships; Using the Structure of Interpersonal Relationships to Understand Individual-to-Individual, Individual-to-Firm, and Firm-to-Firm Relationships in Commerce", International Journal of Research in Marketing, Vol13 No1, pp. 53-72.

Illingworth, J.D. (1991) "Relationship marketing: pursuing the perfect person-to-person relationship", The Journal of Services Marketing, Vol 5 No 4, pp. $49-52$

Javalgi, R. and C.R. Moberg (1997) "Service loyalty: implications for service providers", The Journal of Services Marketing, Vol 11 No 3, pp. 165-179.

Jüttner, U. and H.P. Wehrli (1994) "Relationship marketing from a value system perspective”, International Journal of Service Industry Management, Vol 5 No 5, pp. 5473

Kalwani, Manohar U. and Narakesari Narayandas (1995), "Long-Term ManufacturerSupplier Relationships: Do They Pay Off for Supplier Firms?”, Journal of Marketing, Vol59 (January), pp. 1-16.

Kasper, H., P. van Helsdingen, and W. de Vries (1999) Services Marketing Management - An International Perspective, Wiley, Chichester et al.

Kotler, P. (1997) Marketing Management: Analysis, Planning, Implementation, and Control, $9^{\text {th }}$ ed., Prentice-Hall, Upper Saddle River 
Leigh, Thomas W., David B. MacKay, and John O. Summers (1984), "Reliability and Validity of Conjoint analysis and Self-Explicated Weights: A Comparison", Journal of Marketing Research, Vol. 21 (November), pp. 456-462

Lusch, R.F. and J.R. Brown (1996), "Interdependency, contracting, and relational behaviour in marketing channels", Journal of Marketing, Vol 60 (October), pp. 19-38

Lyons, T.F., A.R, Krachenberg and J.W. Henke (1990) "Mixed motive marriages: what's next for buyer-supplier relations?”, Sloan Management Review, Vol 31 (Spring), pp. 2936

MacNeil, I.R. (1980), The new social contract, an inquiry into modern contractual relations, New Haven, CT: Yale University Press

Mittal, B. and W.M. Lassar (1996) "The role of personalization in service encounters," Journal of Retailing, Vol 72 No1, 95-109

Morgan, R.M. and S.D. Hunt (1994) "The commitment-trust theory of relationship marketing", Journal of Marketing, Vol 58 No 3, pp. 20-38

Punj, G. and D.W. Stewart (1983) "Cluster Analysis in Marketing Research: Review and Suggestions for Application”, Journal of Marketing Research, Vol 20 (May), pp. 134-148

Reicheld, F.F. and Schefter, F. (2000) "E-loyalty, Your Secret Weapon on the Web", Harvard Business Review, Aug/Sept, pp. 105-113

Robicheaux, R.A. and J.E. Coleman (1994), "The Structure of Marketing Channel Relationships", Journal of the Academy of Marketing Science, Vol 22 No1, pp. 38-51.

Rylander, D., D. Strutton, and L.E. Pelton (1997), "Toward a Synthesized Framework of Relational Commitment: Implications for Marketing Channel Theory and Practice", Journal of Marketing Theory and Practice, Vol5 No2, pp. 58-71.

Sharma, N. and P.G. Patterson (1999) "The Impact of Communication Effectiveness and Service Quality on Relationship Commitment in Consumer, Professional Services", Journal of Services Marketing, Vol 13 No2, pp. 151-170

Sheth, J.N. and A. Parvatiyar (1995) "Relationship marketing in consumer markets: antecedents and consequences", Journal of the Academy of Marketing Sciences, Vol 23 No 4, pp. 255-71

Simon, H. (1989), Price Management, Elsevier, Amsterdam.

Storbacka, K., T. Strandvik, and C. Grönroos (1994) "Managing customer relationships for profit: the dynamics of relationship quality", International Journal of Service Industry Management, Vol 5 No5, pp. 21-38 
Sweeny, J.C., G.N. Soutar, and L.W. Johnson (1999) "The role of perceived risk in the quality-value relationship: a study in a retail environment”, Journal of Retailing, Vol 75 No 1, pp. 77-105.

Webster, F.E. (1992) "The changing role of marketing in the corporation", Journal of Marketing, Vol 56 (October), pp. 1-17

Weitz, B.A. and K.D. Bradford (1999) "Personal selling and sales management: a relationship marketing perspective", Journal of the Academy of Marketing Science, Vol 27 No 2, pp. 241-54

Weitz, B. and S.D. Jap (1995), "Relationship marketing and distribution channels", Journal of the Academy of Marketing science, Vol 23 (Fall), pp. 305-20

Westbrook, R.A. and W.C. Black (1985) “A motivation-based shopper typology," Journal of Retailing, Vol 61 No1, pp. 78-103

Wittink, D.R., M. Vriens, and W. Burhenne (1994), "Commercial Use of Conjoint Analysis in Europe: Results and Critical Reflections," International Journal of Research in Marketing, Vol 11, pp. 41-52

Woodruff, R.B. (1997) "Customer value: the next source for competitive advantage," Journal of the Academy of Marketing Science, Vol 25 No 2, pp. 139-53

Yoo, Changjo, Jonghee Park, and Deborah J. MacInnis (1998) "Effects of store characteristics and in-Store emotional experiences on store attitude", Journal of Business Research, Vol 42 No 3, pp. 253-63 
Table 1 Part worths for the total sample Total sample

Service package

Standard

$-, 233$

Plus

$-, 139$

Complete

, 372

Relationship

Incidental

$-1,439$

Informative

, 499

Cooperative

, 940

Price

MSRP $\quad-, 260$

MSRP $-4 \%$

,260 
Table 2 Part worths of attribute levels, segmented by relationship preferences*

\begin{tabular}{lrcr}
\hline & \multicolumn{1}{l}{$\begin{array}{l}\text { Weak } \\
\text { Relationship }\end{array}$} & $\begin{array}{l}\text { Improving } \\
\text { Relationship }\end{array}$ & $\begin{array}{l}\text { Strong } \\
\text { Relationship }\end{array}$ \\
\hline Service package & $\mathrm{N}=159$ & $\mathrm{~N}=271$ & $\mathrm{~N}=313$ \\
Standard &,- 029 &,- 436 &,- 189 \\
Plus &,- 072 &,- 103 &,- 186 \\
Complete &, 101 &, 539 &, 375 \\
Relationship & & & \\
Incidental &,- 297 & $-1,467$ & $-2,011$ \\
Informative &, 247 &, 564 &, 576 \\
Cooperative &, 051 &, 903 & 1,436 \\
Price & & & \\
MSRP &,- 287 &,- 293 &,- 217 \\
MSRP $-4 \%$ &, 287 &, 293 &, 217 \\
\hline
\end{tabular}

* All variables tested simultaneously (MANOVA) show significant differences across the three consumer segments: Wilk's Lambda = .764, F-value $(10 \mathrm{df}): 21.2$, p-value $<.00$.

The Service package variables tested simultaneously (MANOVA) show significant differences across the three consumer segments: Wilk's Lambda $=.983$, F-value $(4 \mathrm{df}): 3.23$, p-value $=.01$.

The Relationship variables tested simultaneously (MANOVA) show significant differences across the three consumer segments: Wilk's Lambda $=.778$, F-value $(4 \mathrm{df}): 49.3$, p-value $<.00$.

The Price variable tested (ANOVA) show significant differences across the three consumer segments: F-value $(2 \mathrm{df}): 1.03, \mathrm{p}$-value $=.36$. 
Table 3 Part worths of attribute levels, segmented by price sensitivity*

\begin{tabular}{lrrr}
\hline & $\begin{array}{l}\text { Always } \\
\text { do business }\end{array}$ & Price sensitive & $\begin{array}{c}\text { Never } \\
\text { do business }\end{array}$ \\
\hline Service package & $\mathrm{N}=301$ & $\mathrm{~N}=257$ & $\mathrm{~N}=147$ \\
$\quad$ Standard &,- 220 &,- 194 &,- 429 \\
Plus &,- 099 &,- 149 &,- 172 \\
$\quad$ Complete &, 319 &, 343 &, 601 \\
Relationship & & & \\
$\quad$ Incidental & $-1,455$ & $-1,422$ & $-1,436$ \\
Informative &, 519 &, 469 &, 533 \\
Cooperative &, 937 &, 954 &, 902 \\
Price & & &,- 322 \\
MSRP &,- 223 &,- 325 &, 322 \\
MSRP $-4 \%$ &, 223 &, 325 & \\
\hline
\end{tabular}

* All variables tested simultaneously (MANOVA) show insignificant differences across the three consumer segments: Wilk's Lambda $=.988$, F-value $(10 \mathrm{df}): 0.87$, p-value $=.57$.

The Service package variables tested simultaneously (MANOVA) show insignificant differences across the three consumer segments: Wilk's Lambda $=.993$, F-value $(4 \mathrm{df}): 1.28$, p-value $=.27$.

The Relationship variables tested simultaneously (MANOVA) show insignificant differences across the three consumer segments: Wilk's Lambda $=.999$, F-value $(4 \mathrm{df}): 0.18$, p-value $=.95$.

The Price variable tested (ANOVA) show significant differences across the three consumer segments: F-value (2 dof): 1.84 , p-value $=.16$. 
Table 4 Part worths of attribute levels, segmented by preferences resulting from using the results of the conjoint study as input for the cluster analysis

\begin{tabular}{lccr}
\hline & Relationship prone & Service-prone & Butterflies \\
\hline Service package & $\mathrm{N}=242$ & $\mathrm{~N}=358$ & $\mathrm{~N}=168$ \\
$\quad$ & & & \\
Standard &, 007 & $-1,186$ & 1,453 \\
Plus &,- 192 &,- 056 &,- 240 \\
$\quad$ Complete &, 185 & 1,242 & $-1,213$ \\
Relationship & & & \\
$\quad$ Incidental & $-3,014$ &,- 920 &,- 279 \\
Informative &, 796 &, 397 & -288 \\
Cooperative & 2,218 &, 523 &,- 009 \\
Price & & & \\
MSRP &,- 141 &,- 394 &,- 147 \\
MSRP $-4 \%$ &, 141 &, 394 &, 147 \\
\hline
\end{tabular}

* Pseudo-testing all variables simultaneously (MANOVA-wise) reveal important differences across the three consumer segments: Wilk's Lambda $=.146$, F-value $(10 \mathrm{df}): 246.2$, p-value $<.00$. These are all pseudo-values. Pseudo testing the Service package variables simultaneously (MANOVA-wise) reveal important differences across the three consumer segments: Wilk's Lambda $=.406$, F-value $(4 \mathrm{df}): 217.5, \mathrm{p}$-value $<.00$. These are all pseudo values.

Pseudo testing the Relationship variables simultaneously (MANOVA-wise) reveal important differences across the three consumer segments: Wilk's Lambda $=.373$, F-value $(4 \mathrm{df}): 243.6$, p-value $<.00$. These are all pseudo values.

Pseudo testing the Price variable (ANOVA-wise) reveal important differences across the three consumer segments: F-value ( 2 dof): 12.8 , p-value $<.00$. These are pseudo values. 


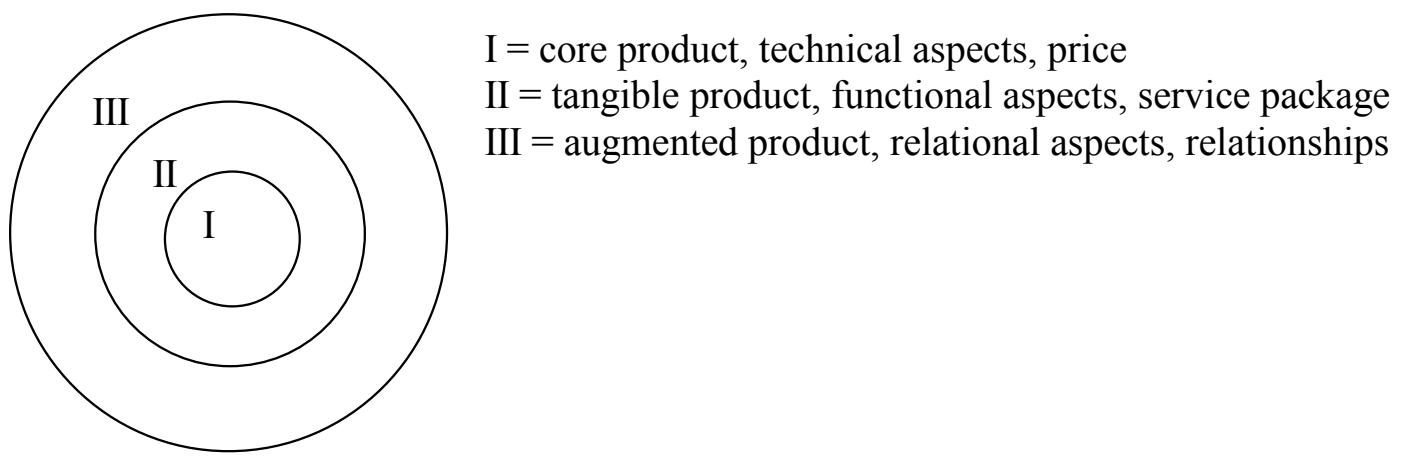

Figure 1 Anatomy of a product model 


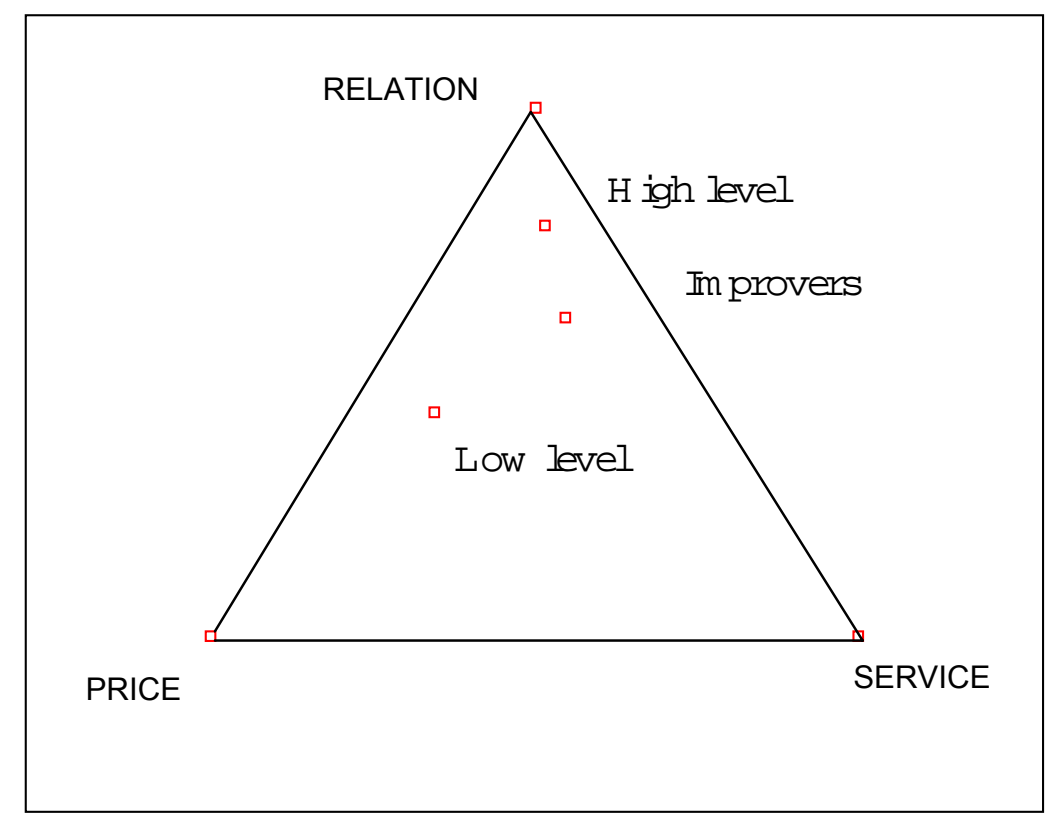

Figure 2 Relative weights of various aspects of the buying process for segments based on relationship characteristics 


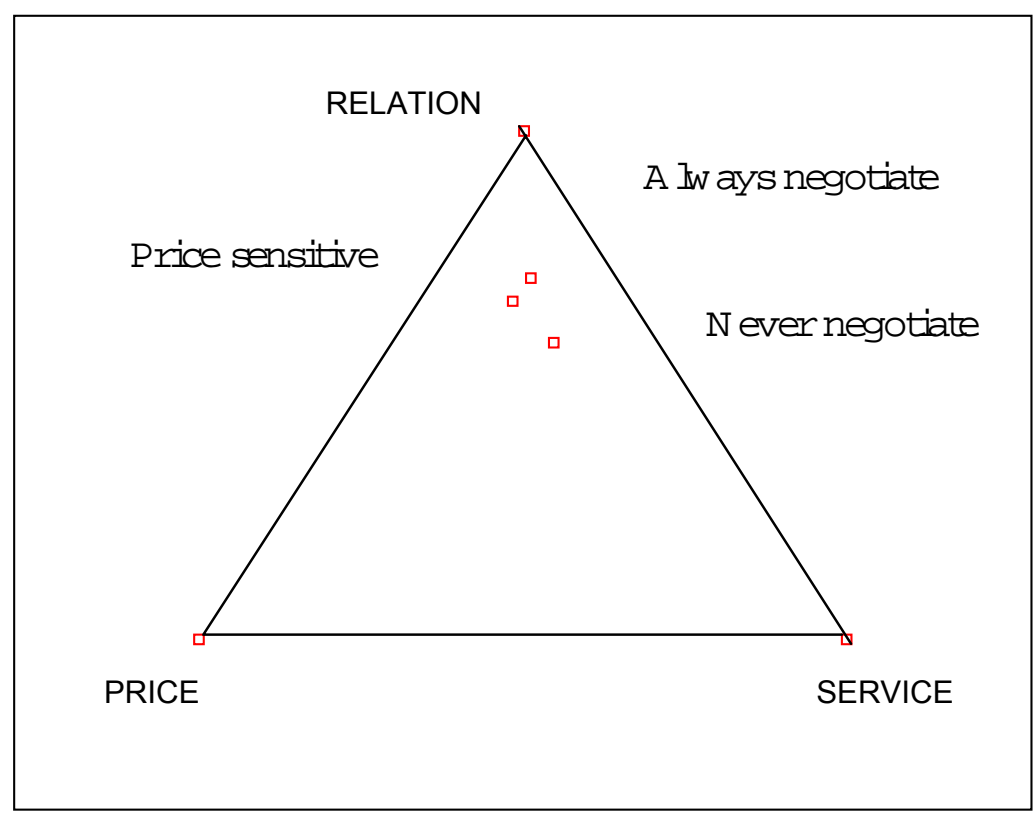

Figure 3 Relative weights of various aspects of the buying process for price segments 


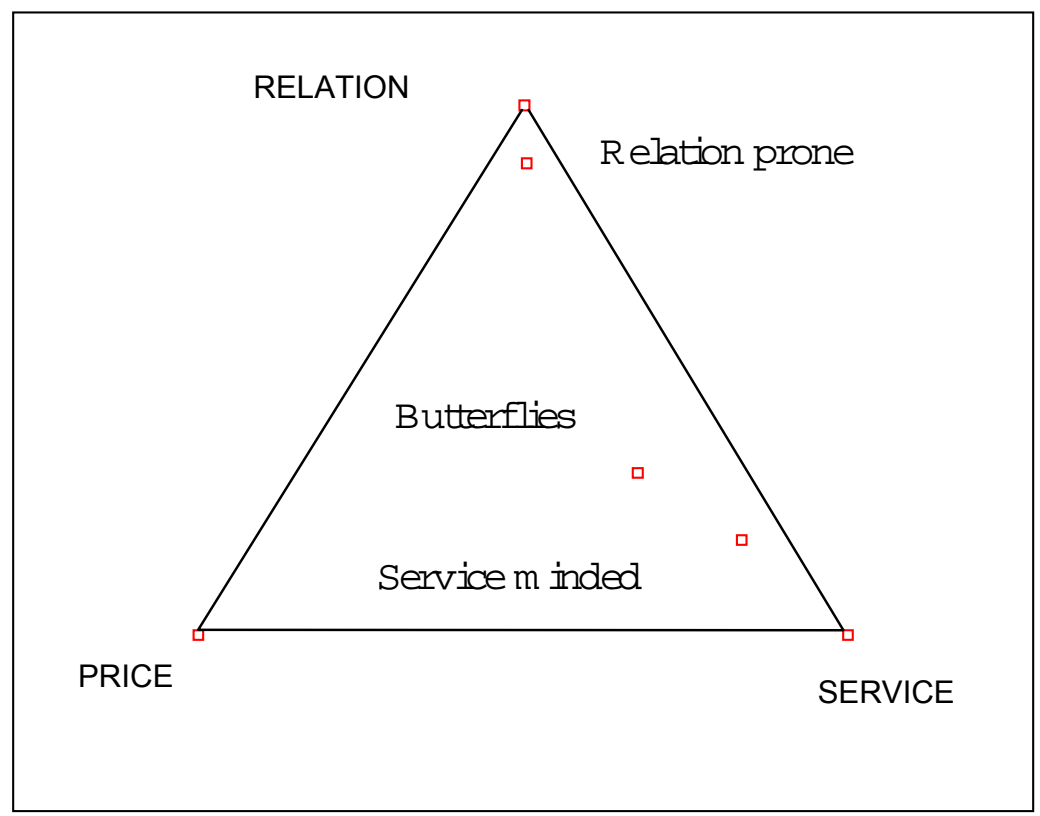

Figure 4 Relative weight of various aspects of the buying process by conjoint based segments 


\section{APPENDIX \\ MEASUREMENT ITEMS}

Stated preferences

\section{$\underline{\text { Relationship }}$}

How would you describe your current relationship with the official dealer of the car brand you currently own/drive (only one answer possible)

I decided not maintain the contact or relationship with the official dealer of the car brand I currently own

Incidental: the car dealer says "Thank you and goodbye" and does not make any other efforts

Awaiting: the car dealer says "Do not hesitate to call me in case of problems" and does not make further efforts

Informative: the car dealer contacts me after the purchase to inform whether I am satisfied with my purchase

Enduring interest: the car dealer frequently shows interest and provides valuable advice

Cooperation: the car dealer is a real partner and we work together to discover ways to effect savings or future product improvements

How would you describe your desired relationship with the official dealer of the car brand you currently own/drive (only one answer possible)

I decided not maintain the contact or relationship with the official dealer of the car brand I currently own

Incidental: the car dealer says "Thank you and goodbye" and does not make any other efforts

Awaiting: the car dealer says "Do not hesitate to call me in case of problems" and does not make further efforts

Informative: the car dealer contacts me after the purchase to inform whether I am satisfied with my purchase

Enduring interest: the car dealer frequently shows interest and provides valuable advice

Cooperation: the car dealer is a real partner and we work together to discover ways to effect savings or future product improvements

\section{Service Package}

We consider three different types of service packages being basic package, complete package, and plus package:

Basic package:

- 1,3 or 5-year guarantee on the car

- excluding the cost of maintenance

Complete package:

- $\quad 1,3$ or 5-year guarantee on the car

- including the cost of maintenance 


\section{Plus package:}

- 1,3 or 5 -year guarantee on the car

- excluding the cost of maintenance

- exchange guarantee: within 2 months after the purchase you can exchange your car for another car

- guarantee for fuel consumption: if the fuel consumption is higher than the standard a financial compensation will be offered

- pre-defined trade-in price after 1,3 or 5 years

Please indicate how much you would be willing to pay for the service packages with your car purchase. You can do this by ticking a box below the category extra payment corresponding to the amount of money you would be willing to pay. If you would not be willing to pay for the service package, please tick a box in the category zero. If you dislike the service package, please tick a box below the category discount that you would like to receive in return for the offered service package (by a discount on the car). Only tick one box per service package.

\begin{tabular}{|c|c|c|c|c|c|c|c|c|c|c|c|c|}
\hline \multirow[t]{2}{*}{ Service Package } & \multirow{10}{*}{ Dfl } & \multicolumn{2}{|c|}{ Discount } & Zero & \multicolumn{8}{|c|}{ Extra payment } \\
\hline & & 1000 & 500 & 0 & 500 & 1000 & 1500 & 2000 & 2500 & 3000 & 3500 & 4000 \\
\hline 1 year plus & & $\square$ & $\square$ & $\square$ & $\square$ & $\square$ & $\square$ & $\square$ & $\square$ & $\square$ & $\square$ & $\square$ \\
\hline 1 year complete & & $\square$ & $\square$ & $\square$ & $\square$ & $\square$ & $\square$ & $\square$ & $\square$ & $\square$ & $\square$ & $\square$ \\
\hline 3 years basic & & $\square$ & $\square$ & $\square$ & $\square$ & $\square$ & $\square$ & $\square$ & $\square$ & $\square$ & $\square$ & $\square$ \\
\hline 3 years plus & & $\square$ & $\square$ & $\square$ & $\square$ & $\square$ & $\square$ & $\square$ & $\square$ & $\square$ & $\square$ & $\square$ \\
\hline 3 years complete & & $\square$ & $\square$ & $\square$ & $\square$ & $\square$ & $\square$ & $\square$ & $\square$ & $\square$ & $\square$ & $\square$ \\
\hline 5 years basic & & $\square$ & $\square$ & $\square$ & $\square$ & $\square$ & $\square$ & $\square$ & $\square$ & $\square$ & $\square$ & $\square$ \\
\hline 5 years plus & & $\square$ & $\square$ & $\square$ & $\square$ & $\square$ & $\square$ & $\square$ & $\square$ & $\square$ & $\square$ & $\square$ \\
\hline 5 years complete & & $\square$ & $\square$ & $\square$ & $\square$ & $\square$ & $\square$ & $\square$ & $\square$ & $\square$ & $\square$ & $\square$ \\
\hline
\end{tabular}

\section{$\underline{\text { Price }}$}

Imagine you intend to purchase a new car. The price is fixed and not negotiable, which means that no discount will be provided. Are you willing to do business with this car dealer?

$\square$ yes
$\square$ no

Imagine you intend to purchase a new car. The price is fixed and not negotiable. However the price is equal to the manufacturer's suggested retail price minus $4 \%$. Are you willing to do business with this car dealer?

$$
\square \text { yes }
$$

$\square$ no

Revealed preferences (conjoint analysis)

\section{Relationship, service package, and price}

Below, you will see several service-packages representing a possible purchase situation of car. Each package consists of a combination of factors that might be important in purchasing a car. Two different assumptions are applied:

- The first five packages assume a situation in which the price of the car is equal to the manufacturer's suggested retail price. 
- The final four packages assume a situation in which the price of the car is equal to the manufacturer's suggested retail price minus $4 \%$

Please assign a score to each package, representing your preference for that particular package: $1=$ absolutely no preference and $9=$ very strong preference

$\begin{array}{llllllllllll}\text { Assume the price of the car is equal to } & & 1 & 2 & 3 & 4 & 5 & 6 & 7 & 8 & 9\end{array}$ the manufacturer's suggested retail price

and

- $\quad$ you receive a standard service package: 3 years guarantee, excluding the cost of maintenance

- $\quad$ your relationship with the car dealer is Incidental: the car dealer says "Thank you and goodbye" and does not make any other efforts

Assume the price of the car is equal to $\quad \begin{array}{llllllllll}1 & 2 & 3 & 4 & 5 & 6 & 7 & 8 & 9\end{array}$ the manufacturer's suggested retail price $\quad \square \quad \square \quad \square \quad \square \quad \square \quad \square \quad \square \quad \square \quad \square$ and:

- you receive a standard service package: 3 years guarantee, excluding the cost of maintenance

- your relationship with the car dealer is cooperative: the car dealer is a real partner and we work together to discover ways to effect savings or future product improvements

Etc. 